\title{
Investigating the Dynamic response of Electrohydraulic Servo Motor
}

\author{
S. Selim ${ }^{(1)}$, M. Abdel-Aziz ${ }^{(2)}$, M.G. Rabie ${ }^{(3)}$ and M.A. Moharm $^{(4)}$ \\ ${ }^{1,2,4)}$ Mechanical Power Engineering Department, Faculty of Engineering, Menoufiya \\ University, Shebin El-Kom, EGYPT \\ ${ }^{3)}$ Industrial Engineering Department, Faculty of Engineering, Modern Academy, EGYPT
}

\begin{abstract}
Dynamic response of electro-hydraulic servo systems (EHSS) is complex and its characteristics are highly nonlinear. These nonlinear features need to be discussed and modeled as electro-hydraulic servo systems are now the main muscle a lot of applications that need a precise and fast control. Therefore, a detailed and precise mathematical model needs to be deducted to get an effective controller design procedure. The goal of this work is to develop a mathematical model, simulated model using Simulink program and control method using an effective controller for Electro- hydraulic servo motor (EHSM). These concepts will allow studying, analysis and control of the dynamic characteristics of EHSM velocity and position. To demonstrate the effectiveness of this analysis the experimental work has been done via Electro-hydraulic servo mechanism EHS 160, DAQ NI 6008 and Simulink program.
\end{abstract}

Keywords: Electrohydraulic servo systems, Hydraulic servo motors, EHS 160, MATLABSIMULINK, P controller

\section{INTRODUCTION}

The hydraulic technology has been well developed in industry since its first applications at the end of the 18th century. This type of systems widely used due its advantages over electro-mechanical systems, [1]. Electrohydraulic servo actuators (EHSAs) are the main components of many hydraulic systems used for variety of applications such as control of aircraft surfaces such as rudders, elevators, slats and undercarriage, [2]. Regarding to military applications, EHSAs has been used for Antenna elevation, point actuation, level actuation and missile steering and turret stabilization, [3]. Also, they are heavily used in automotive industries, transportation, mining, construction, agriculture, four-wheel driving, modern driving and flight or driving simulator, [4].

All of these applications require closed-loop hydraulic control systems that offer high levels of automation performance, power and energy efficiencies. The increasing use of electronics components to control all types of hydraulic systems has naturally led to greater interest in servo and proportional valves, [5] that deliver outstanding response and fluid pressure as well as flow rates. Closed loopelectro hydraulic servo drives technology is increasingly becoming the norm in machine automation, [6] than proportional valves, where the operators are demanding greater precision, faster operation and simpler adjustment. In These applications, the highest performance of the electrohydraulic motors can be obtained by introducing more effective design for hydraulic components or setting their velocity and position by using an effective and a suitable controller. The proportional-integral-derivative (PID) controllers are widely applied with the electro-hydraulic servo system since it is easily to implement and highly efficient, [7]. In Ref [4], authors discussed the dynamic performance analysis of PID and Fuzzy logic controllers applicable in electro hydraulic servo actuators. They concluded that PID controller is simpler in construction and produces good results that satisfy the requirements and criteria of a stable control system. In addition, the performance of fuzzy logic controller was better as it produces a fast response without oscillation, and this is very suitable for high precision applications such as microelectronics, robotics, military and nuclear applications. Moreover, in Ref [8], author investigated PID Parameters optimization using genetic algorithm technique for electrohydraulic servo actuator control system and demonstrated that the optimized PID improve the performances of the hydraulic servosystem in order to achieve minimum settling time with no overshoot and nearly zero steady state error. Pseudo derivative feedback system is discussed and investigated in [9], a remarkable improvement for the control system of electro hydraulic servo system introduced. The main objective of this present paper is to achieve an improvement to the dynamic performance of electro hydraulic servo motor 
(EHSM) to maintain a high level of accuracy. Accordingly, the major goal of this paper is to develop a mathematical model, Simulink model and an effective controller to analyze and control the dynamic characteristics of electrohydraulic servo motor EHSM velocity. To verify the effectiveness of the model, experimental work has been conducted using EHS 160 electro hydraulic servo mechanism.

\section{Electrohydraulic servo motor system configura-} tion.

The experimental work was conducted using the electro hydraulic servo mechanism EHS 160 at automatic control laboratory, faculty of engineering, Menuf, Menofia University. Schematic diagram of hydraulic circuit is illustrated in Fig. 1.

The hydraulic system of EHS160 mechanism components are shown in figures (1) and (2) that is a real system built in Lab and figure (3) that is the control block diagram.

The test rig consists of:

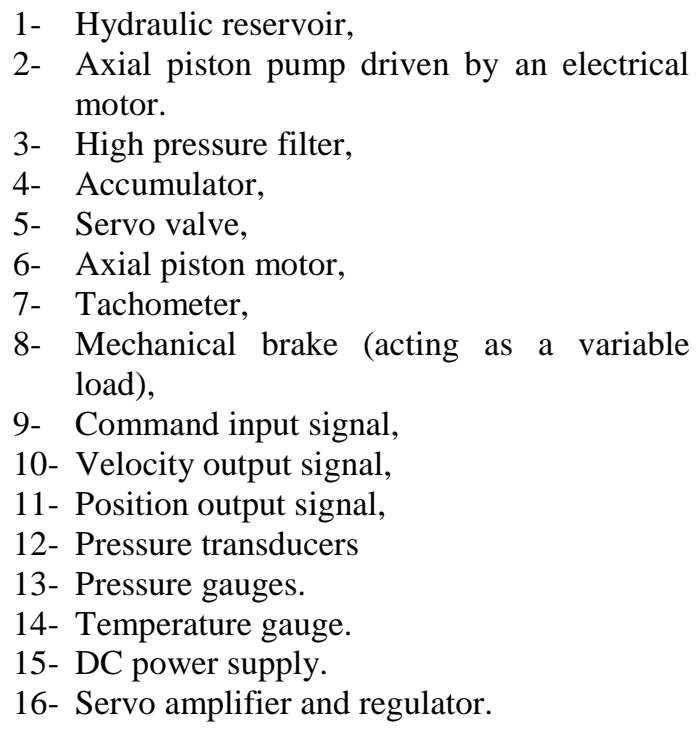

An electrical motor driven hydraulic fixed pump (2) transports the oil from the reservoir (1) through flexible pressure tubing to the pressure side of the servovalve (5). The supply pressure in the power unit, measured by pressure gauge (13) and pressure transducer (12), will be held at a constant value (70 bars) by a pressure relief valve.

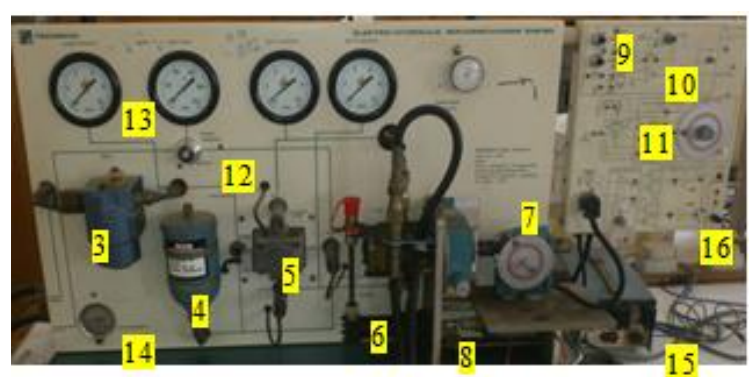

Fig.1. Schematic Diagram of the Experimental Test setup

The outputs of the servo-valve control the hydraulic motor (6) through two hydraulic hoses. The hydraulic motor transforms the hydraulic pressure or a hydraulic oil flow into a moment or angular velocity. Another engine or a load can be driven by the drive shaft of the hydraulic motor. A flywheel mass on the driving shaft of the hydraulic motor can be braked by a shoe brake (8). The output of the servo motor is measured with a transducer device, tachometer, (7) that convert the angular speed into a voltage proportionally to the angular speed. This signal work as a feedback signal (10), fed to a servo valve amplifier (16) and compared with the command signal (9). The resulting error signal is then amplified by the regulator and the electric power amplifier, via $220 / 24$ volt dc supplier (15), and then used as an input control signal to the servo valve. The servo valve controls the fluid flow to the motor in proportion to the drive current from the amplifier. The motor then forces the load to move. Thus, a change in the command signal generates an error signal, which causes the load to move in an attempt to zero the error signal. If the amplifier gain is high, the output will vary rapidly and accurately following the command signal. The controller will be connected to a PC with MATLAB SIMULINK via DAQ NI 6008

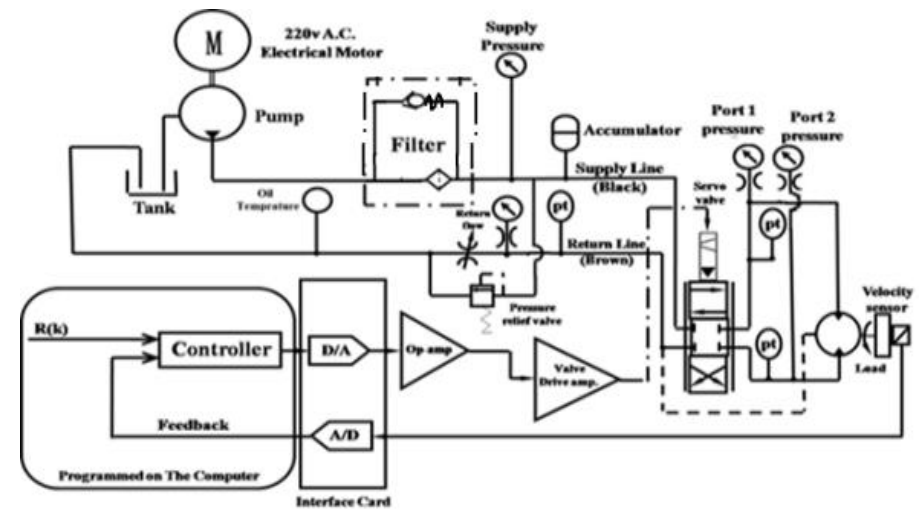

Fig.2. Real system of EHS 160 servomechanism 
3. Electrohydraulic servo motor system mathematical modeling.

The main structure of the studied system is shown in figure (4). An axial piston motor (type LUCAS PM series) is controlled by DAWTY 4551.163 servo valve.

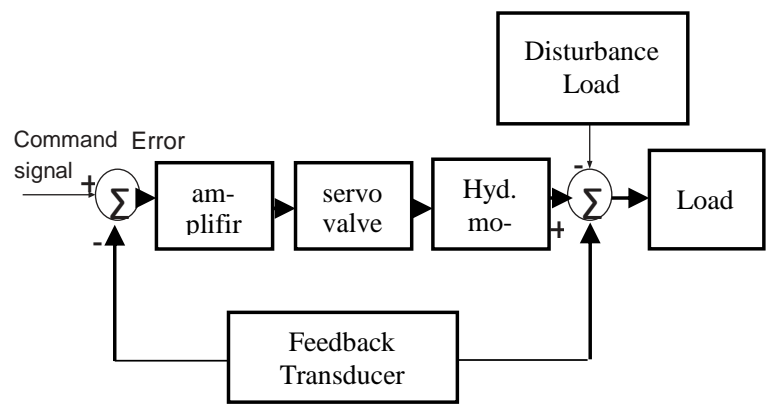

Fig.3. control block diagram of EHS 160.

The dynamic model is developed under the following assumptions:

i. The supply pressure is constant.

ii. Servo valve orifices are matched and symmetrical.

iii. Valve flow is modeled by turbulent flow through sharp-edged orifices.

iv. Motor external leakage is negligible.

The development of mathematical model of such systems should include the non-linear dynamic effects to obtain the correct mathematical treatment [10]. For an ideal oil supply, the model of EHSS is composed of two subsystems:

1- Two stage electro hydraulic servo valve.

2- Hydraulic motor.

And the valve is connected to a hydraulic rotary actuator by very short hoses.

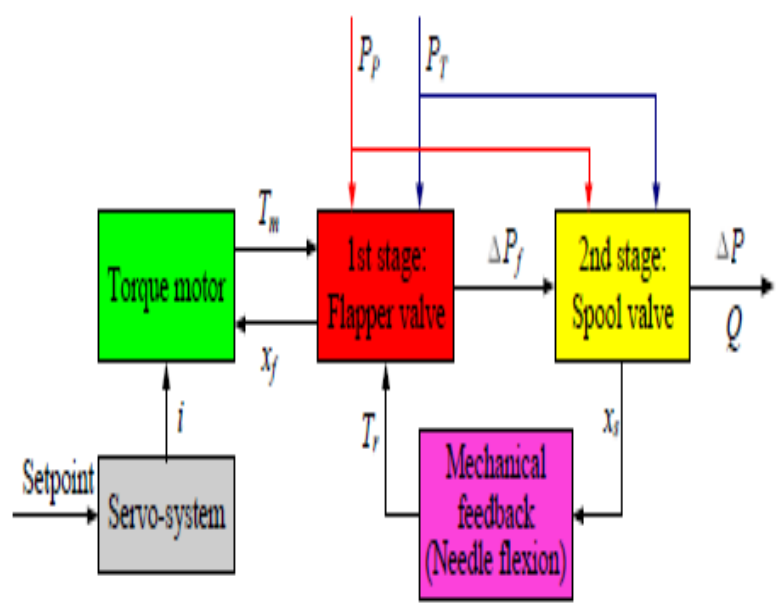

Fig.5. Structure of electro hydraulic servo valve

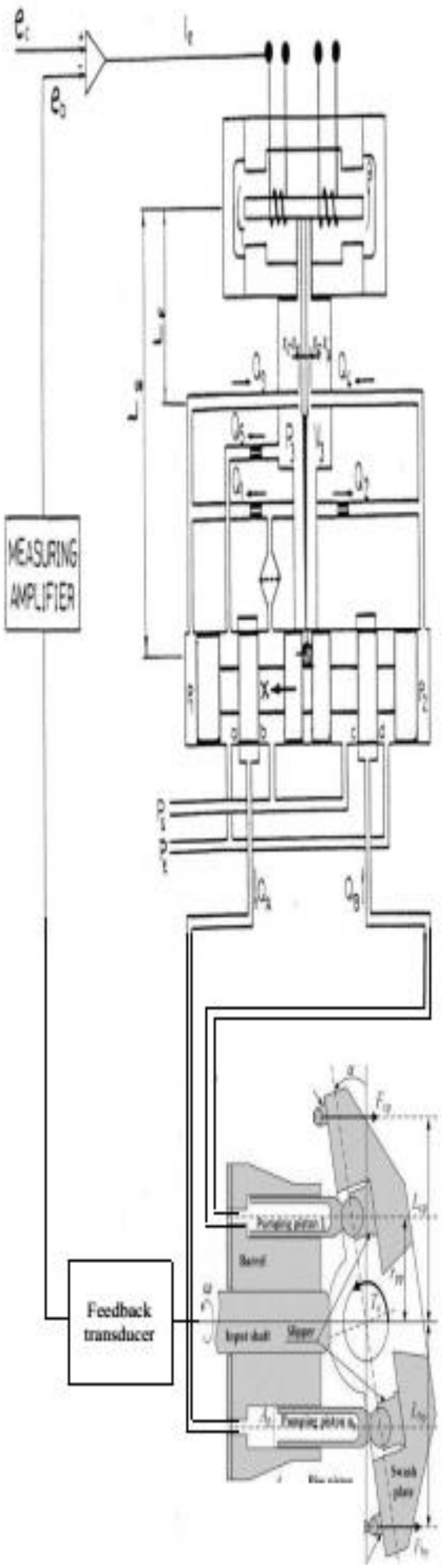

Fig.4. structure of electro hydraulic servo motor 


\subsection{Electro hydraulic servo valve modeling.}

The structure of the two- stage electro hydraulic servo valve under study is illustrated by figure (5). The electro hydraulic servo valve consists of a torque motor that convert the electrical signal received from servo controller and amplifier to angular movement, $1^{\text {st }}$ stage (flapper valve) that is connected to the torque motor via a flapper inside a flexure tube , $2^{\text {nd }}$ stage (spool) that is connected to flapper valve by a feedback spring .

The hydraulic motor angular velocity $\theta$ is picked up by a tachogenerator transducer and fed back to the electronic controller, which generates the corresponding error signal.

As the amplification element, the servo amplifier amplifies the error signal, which is relatively weak, to realize the control of the torque motor, the feedback loop can be described by following equations:

$$
\begin{aligned}
& i_{x}=i_{c}+i_{b} \\
& i_{b}=K_{F B} \theta
\end{aligned}
$$

Where $i_{x}, i_{c}$ and $i_{b}$ are torque motor input current, control (reference) input current and feedback current respectively, $K_{F B}$ is the feedback gain.

For ${ }^{1 s t}$ stage, when the coil of torque motor energized by input signal, a proportional magnetic charge in the armature and it has a rotational movement deflection that transferred to flapper valve via a flapper extended through a flexure tube. The flapper passes between two nozzles creating to variable orifices, when the flapper moved toward any nozzle, it makes a deferential oil flow and pressure inside the flapper valve, this differential pressure actuating the valve spool, the valve spool movement causes a torque in the feedback spring which oppose the torque in armature, or the $1^{\text {st }}$ stage the differential oil flow $Q_{f}$ can be expressed by:

$$
Q_{f}=i_{x} k_{f}-X_{s} K_{s f}
$$

Where $k_{f}, X_{s}$ and $K_{s f}$ are flapper gain constant, spool displacement and spool- flapper feedback constant.

For $2^{\text {nd }}$ stage, the proportional spool displacement is controlled by the differential flow of flapper, the spool travel speed can be described by:

$$
X_{s}=Q_{f} / A_{s}
$$

Where $A_{S}$ is the spool cross section end.

$$
X_{S} A_{S}+X_{S} K_{s f}={ }_{i}{ }_{x} f
$$

Using Laplace transformation,

The spool displacement can be given by:

$$
X_{s}\left(A_{s} s+K_{s f}\right)=i_{x}{ }^{k} f
$$

Then the transfer function describing the electrohydraulic servo valve where the oil flow generated of the valve port $Q$ is the output and the differential current $i_{x}$ is the input can be expressed by:

Equations (3) and (4) can be written as:

$$
\frac{Q(s)}{i_{X}(s)}=\frac{K_{S} X_{S}(s)}{i_{X}(s)}=\frac{K_{s} K_{f} / K_{s f}}{1+S_{\tau_{X}}}
$$

Where $\tau_{x}=A_{S} / K_{S f}$ is the valve time constant, and $K_{S}=Q / X_{S}$ is the spool displacement- flow constant.

The steady state value of the $Q / V_{x}$ is $K_{x}$, where $i_{x} / V_{x}$ is constant. Therefore, the transfer function describing the electro hydraulic servo valve using valve flow gain $K_{x}$ and amplifier input volt $V_{x}$ can be written as:

$$
\frac{Q(s)}{V_{x}(s)}=\frac{K_{x}}{1+s \tau_{x}}
$$

The flow $Q$ generated from servo valve due to spool displacement can be given by:

$$
Q=K_{x} V_{x} \sqrt{\left(P_{s}-\frac{\left|P_{x}\right|}{P_{s}}\right)}
$$

Where $P_{S}$ and $P_{x}$ are the supply pressure and the valve output pressure respectively.

According to equation (9) $Q \alpha \sqrt{P}$ which is a nonlinear relation between the flow and pressure inside electro hydraulic servo valve

\subsection{Hydraulic axial piston motor modeling}

The losses inside the hydraulic motor can be assumed due to friction and viscous losses (neglecting kinetic and stiction losses) the corresponding pressure drop $P_{f}$ is

$$
P_{f}=\theta T_{v f}+T_{c f}
$$


Where $T_{v f}$ is viscous friction / $(\mathrm{rad} / \mathrm{sec})$ and $T_{c f}$ is the velocity -independent friction torque.

$$
P_{f}=\frac{Q T_{v f}}{100 V_{m}^{2}}+\frac{T_{c f}}{100 V_{m}}
$$

The valve output pressure $\left(P_{x}\right)$ can be expressed by:

$$
P_{x}=P_{L}+P_{f}
$$

Combining equations (11) and (12)

$$
P_{x}=\frac{Q T_{v f}}{100 V_{m}^{2}}+\frac{T_{c f}+T_{L}}{100 V_{m}}
$$

Where $V_{m}$ is the motor displacement.

The motor has three factors which predominantly control its high frequency, the inertia $J$ of the rotating parts of motor plus the contained oil plus load, damping $B$ due viscous effects and the compressibility of oil contained in the motor between the drive ports and the piston faces causing effective spring stiffness $K$. The valve output pressure actuated the motor can be obtained as follows:

$$
\begin{gathered}
P_{X}=\frac{\overrightarrow{\partial \theta}}{V_{m}}+Y V_{m} \dot{\theta}+\frac{T}{V_{m}} \\
T=T_{L}+T_{c f} \\
Y=\frac{\partial P_{f}}{\partial Q}
\end{gathered}
$$

Where $T$ is the total torque of the load and the motor, $T L$ is the load torque, $T_{c f}$ is the torque due to friction and $Y$ is the viscous loss constant

The motor is fed with flow independent of the back pressure from the motor and $\frac{\partial p}{\partial Q}$ characteristics of the servo valve and add to those in the motor. Accordingly a proportion of input flow is dependent on the motor pressure. The total flow can be given by

$Q=$ active flow + compression flow + leakage + effect of pressure on flow source.

For symmetrical 4-port operation,

$Q=V_{m} \dot{\theta}+\frac{\left(V_{c} / 2\right)}{K_{b}} \frac{P_{x}}{2}+Z P_{x}$
Where $V_{c}$ is motor fractional contraction volume, $K_{b}$ is oil bulk modulus, $Z$ is the source stiffness and motor leakage equivalent [10]

$$
Z=\operatorname{source} \frac{\partial Q}{\partial_{P x}}+K_{l}
$$

Where $K_{l}$ is the equivalent leakage coefficient.

Combining equations (14) and (17) and notation of Laplace transformation, the flow expression of hydraulic motor can be introduced as the flow rate dependent in pressure (the input of the hydraulic motor) and the angular velocity (the output of the hydraulic motor)

$$
\begin{aligned}
& Q(s)=\left[\begin{array}{c}
\frac{V_{c} J}{4 K_{b} V_{m}} S^{2}+ \\
\left(\frac{Y V_{m} V_{c}}{4 K_{b}}+\frac{Z J}{V_{m}}\right) S \\
+(1+Y Z) V_{m}
\end{array}\right] \theta^{\bullet}(s) \\
& +\left(Z+\frac{V_{c}}{4 K_{b}} s\right) \frac{T(s)}{V_{m}}
\end{aligned}
$$

The hydraulic motor transfer function can be described by:

$$
\begin{gathered}
\frac{\theta^{\bullet}(s)}{Q(s)}=\frac{1}{V_{m}} X \frac{4 K_{b} V_{m}^{2} / V_{c} J}{S^{2}+\left(Y_{V_{m}}^{2}+\frac{4 Z_{K_{b} J}}{V_{c}}\right) \frac{S}{J}} \\
+\frac{4 K_{b} V_{m}^{2}}{V_{c} J}(1+Y Z)
\end{gathered}
$$

Therefore the transfer function of the hydraulic motor and the load can be given by

$$
\frac{\theta^{\bullet}(s)}{Q(s)}=\frac{1}{V_{m}} X \frac{K / J}{S^{2}+(B / J) S+K / J}
$$

Where $K=\frac{{ }^{4} K_{b} V_{m}^{2}}{V_{c}}$ is the motor stiffness equivalent and,

$B=Y V_{m}^{2}$ is the motor damping equivalent.

Knowing the component characteristics, determining the flow and pressure in the normal operating conditions and combining the steady- state expressions of the valve and motor give the overall steady-state expression of the electro hydraulic servo motor systems. 


\section{EHSM Experimental investigation}

The experimental setup is arranged to estimate and compare the results of mathematical model for electro hydraulic servo motor system. A real time photo of the experimental HSS is illustrated in Figure (6). The servomechanism EHS 160 used in this experimental work is constructed by FEEDBACK INSTRUMENTS LIMITED. Table -1 illustrates the major items of the servo:

\begin{tabular}{|l|l|}
\hline \multicolumn{2}{|c|}{ Table -1 servo mechanism items data } \\
\hline $\begin{array}{l}\text { Hydraulic } \\
\text { power supply }\end{array}$ & $\begin{array}{l}\text { FEEDBACK INSTRUMENTS, } \\
\text { Type HPS161, Shell Tellus 27 oil }\end{array}$ \\
\hline$\underline{\text { Servo Valve }}$ & Dowty 4551 \\
\hline $\begin{array}{l}\text { Hydraulic } \\
\text { motor }\end{array}$ & Lucas pm 60 series, 5 pistons \\
\hline$\underline{\text { Data acquisition }}$ & NI 6008 \\
\hline$\underline{\text { Lap top }}$ & Dell core i5 \\
\hline$\underline{\text { Tachogenerator }}$ & SE 254 \\
\hline$\underline{\text { PID set }}$ & $\begin{array}{l}\text { FEEDBACK INSTRUMENTS LIM- } \\
\text { ITED }\end{array}$ \\
\hline $\begin{array}{l}\text { Electronic } \\
\text { power unit }\end{array}$ & $\begin{array}{l}\text { FEEDBACK INSTRUMENTS LIM- } \\
\text { ITED, +15v and -15 volt, 50 Hz }\end{array}$ \\
\hline
\end{tabular}

Supplying servo controller with +15 volt, -15 volt and earth inputs via electronic power unit.

Connecting the required outputs, input current- tachogenator signal- valve input signal, to NI 6009 card.

Setting up interface programing between NI 6009 card and MATLAB data acquisition app.

\section{System identification and validation}

The dynamic response of EHSM can be obtained to construct a mathematical model based on measured input-output data using system identification techniques. System identification can be either an input-output model form which is identical to the transfer function representation or in state space form; models with state space representation allow identification of multi-input multi-output systems. Using electro hydraulic servo valve transfer function and hydraulic motor transfer function with system identification Toolbox in MATLAB SIMULINK, a simulation model can be achieved based on these transfer functions and the system components physical parameters showed in Table- 2 [10].

\begin{tabular}{|c|c|c|c|c|}
\hline \multicolumn{5}{|c|}{ Table -2 System physical prosperities } \\
\hline Valve & $\begin{array}{l}\tau x \\
\mathrm{~K}_{\mathrm{a}} \\
\mathrm{K}_{\mathrm{x}} \\
\end{array}$ & $\begin{array}{l}\text { valve time constant } \\
\text { operational amplifier gain } \\
\text { valve flow gain at } \mathrm{Pl}=0\end{array}$ & $\mathrm{~s}$ & $\begin{array}{l}2.3 \times 10^{-3} \\
-1 \\
-1.36 \times 10^{-4}\end{array}$ \\
\hline Motor & $\begin{array}{l}V_{c} \\
V_{m} \\
L_{e} \\
K_{h}\end{array}$ & $\begin{array}{l}\text { volume of oil in motor and hoses } \\
\text { motor displacement } \\
\text { equivalent leakage coefficient } \\
\text { hydraulic bulk modulus }\end{array}$ & $\begin{array}{l}\mathrm{m}^{3} \\
\mathrm{~m}^{3} / \mathrm{rad} \\
\mathrm{m}^{5} / \mathrm{Ns} \\
\mathrm{N} / \mathrm{m} 2\end{array}$ & $\begin{array}{l}20.5 \times 10^{-6} \\
0.716 \times 10^{-6} \\
2.8 \times 10^{-11} \\
1.4 \times 10^{9}\end{array}$ \\
\hline$\underline{\text { Load }}$ & $\begin{array}{l}B_{e} \\
J \\
T_{f}\end{array}$ & $\begin{array}{l}\text { equivalent viscous coefficient } \\
\text { motor inertia } \\
\text { magnitude of coulomb-friction }\end{array}$ & $\begin{array}{l}\text { Nms/rad } \\
\text { Nms2/rad } \\
\text { N.m }\end{array}$ & $\begin{array}{l}2.95 \times 10^{-3} \\
0.4 \times 10^{-3} \\
0.225\end{array}$ \\
\hline \multirow[t]{3}{*}{ Transducer } & $\overline{\mathrm{K}_{\mathrm{t}}}$ & tachogenerator constant & $\mathrm{v} / \mathrm{rad} / \mathrm{S}$ & 0.026 \\
\hline & $\mathrm{K}_{\mathrm{s}}$ & position transducer constant & $\mathrm{v} / \mathrm{rad}$ & 3.44 \\
\hline & $\mathrm{n}$ & gear ratio & & 7.5 \\
\hline
\end{tabular}

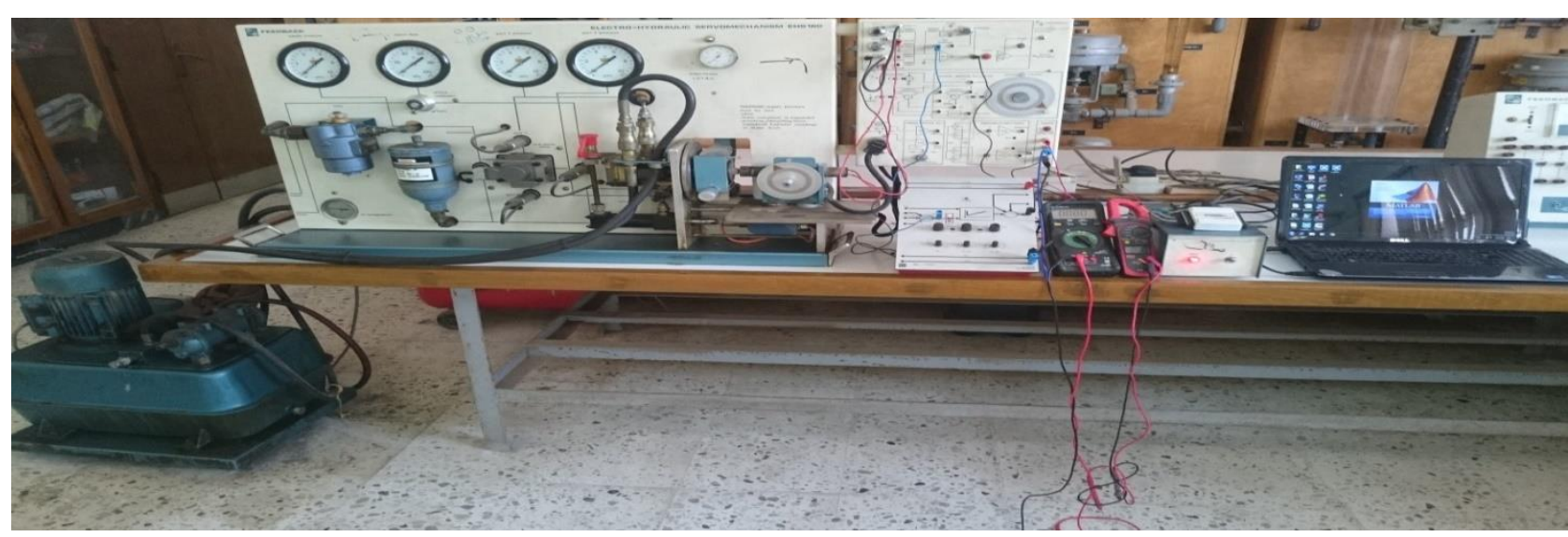

Fig. (6) Real time photo of EHSM 160 
System Identification Toolbox in MATLAB used to construct mathematical models of dynamic systems based on measured experimental input-output data. Time domain and frequency domain input-output data can be used to identify continuous time, discrete time transfer functions, process models, and state space models. The model quality is usually measured in terms of the error between the experimental or measured output and the real time model output. The Toolbox result is found as $97.9 \%$ between experimental and mathematical model.

\section{Simulation and experimental results and discussion} The time responses of the system are obtained experimentally with respect to multi step inputs and load disturbances. Experimental work is based on open loop and closed loop readings. Figure (7) represented online step input signal for the electrohydraulic servo valve amplifier.

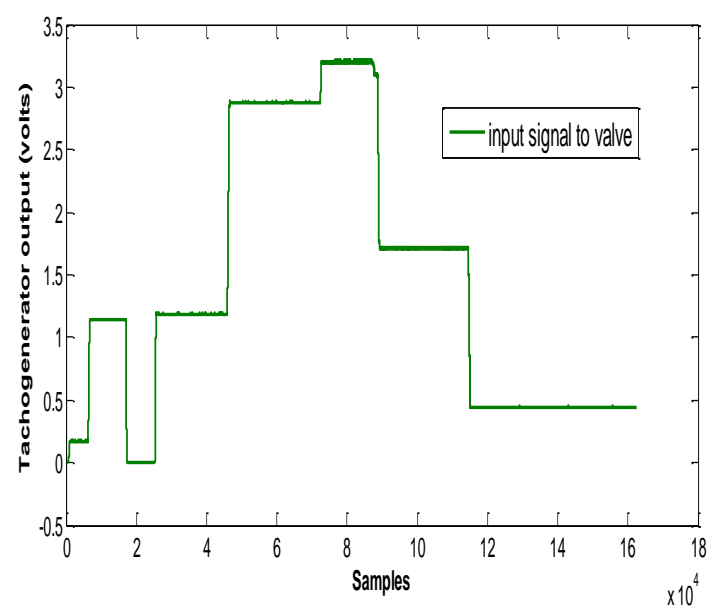

Fig.(7) Step input signal to valve

Open loop dynamic response of the studied system is investigated theoretically and during experiments under variable step inputs and load disturbances.

Figures (8) and (9) describe the experimental and simulation open loop response of the electro hydraulic servo motor system. It shows that a steady state error $(\mathrm{SSE}=2.89)$ is existed and overshoot.

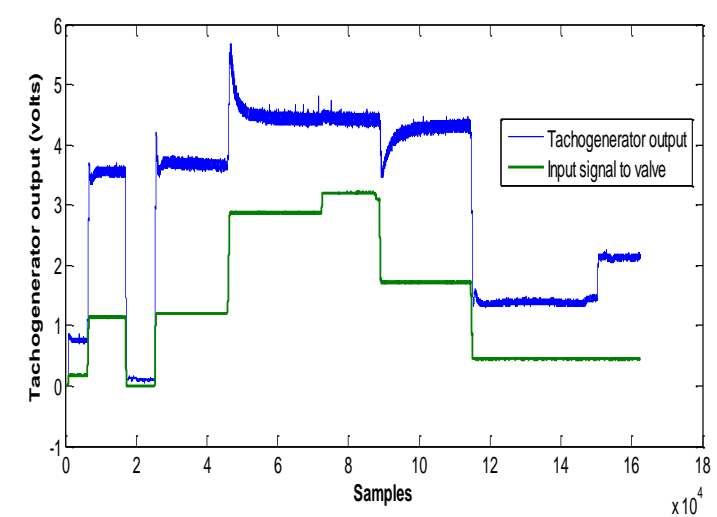

Fig. (8) Open loop output versus valve input
A good agreement between experimental data and simulation model is observed, and comparing with the simulated one for the same input and found they fitted by $97.9 \%$.

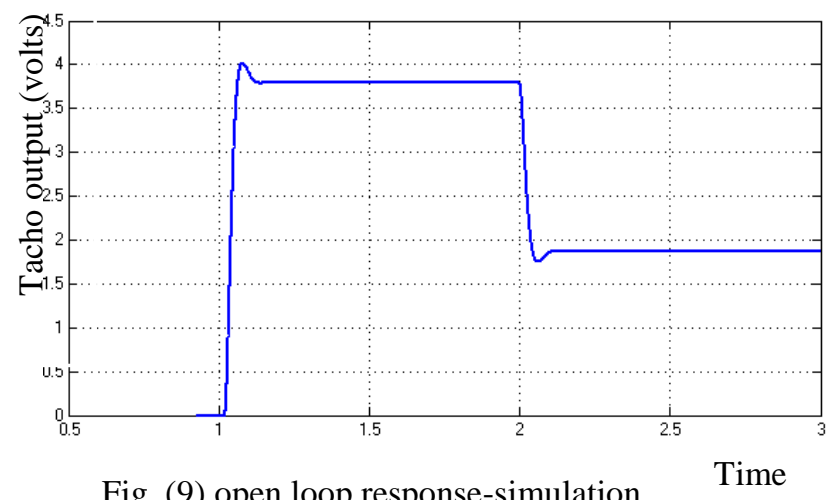

Fig. (9) open loop response-simulation

Figure (10) describe the experimented and simulated open loop response for unit step input of the electro hydraulic servo motor. It shows that the transient response of electrohydraulic servo motor has settling time of (ts $=0.9 \mathrm{~s})$, rise time of $(\mathrm{tr}=0.5 \mathrm{~s})$ and steady state error $(\mathrm{SSE}=2.8)$. It is clear that the output of the system under no control is far from the desired output, which implies the need of predictive, adaptive or conventional controller
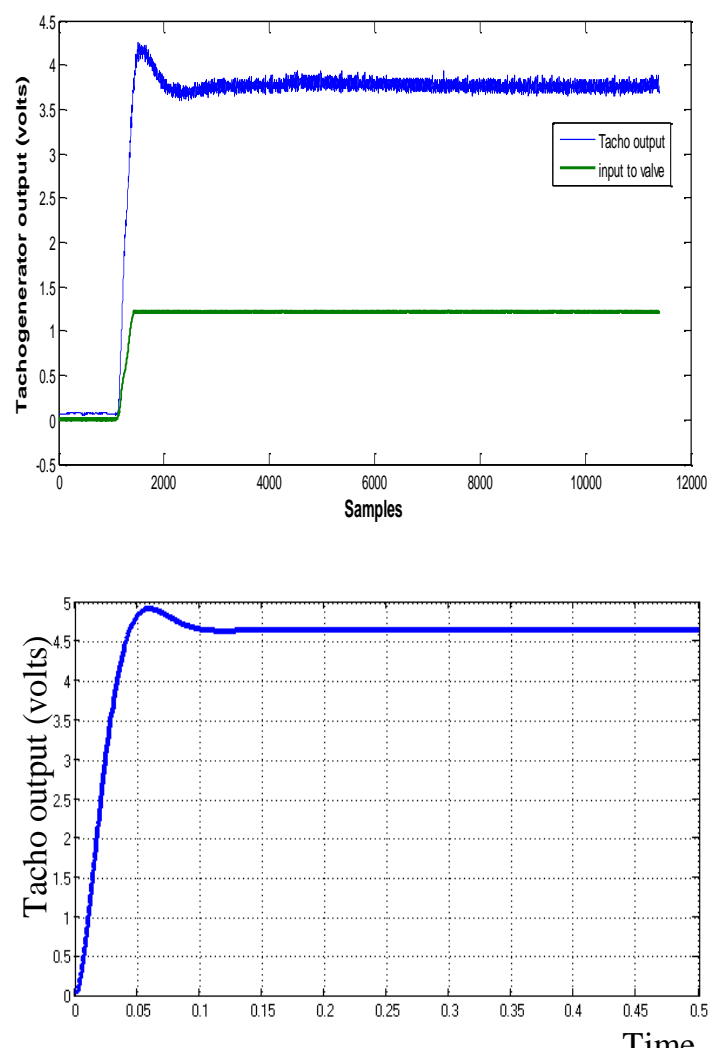

Fig(10) open loop response to unit step 
Figure (11) indicates that the open loop output of tachogenerator output is decreased when a load disturbance is applied to the motor shaft and the system couldn't make up for this decrees until the valve input is increased.

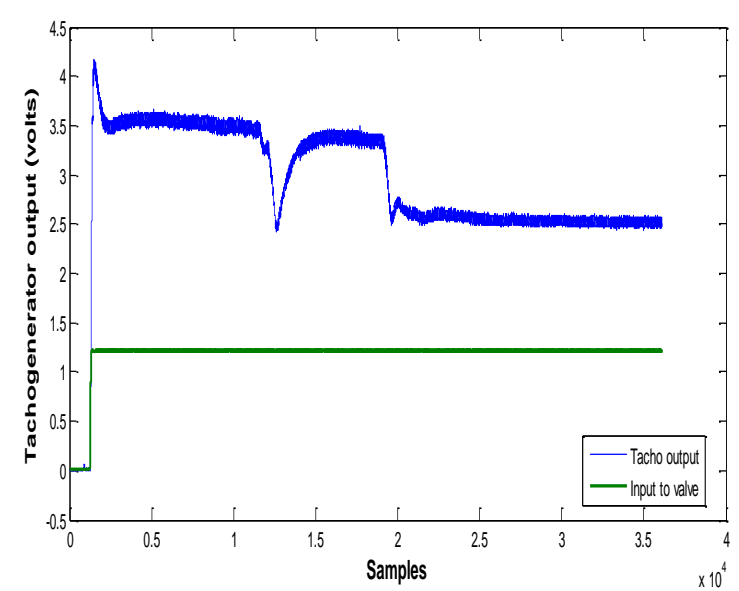

Fig. (11) open loop response under load disturbances

Introducing a proportional $\mathrm{P}$ - controller $\mathrm{Kb}=0.105$ for the studied system shown in figure (12). The results for settling time ts $=0.6 \mathrm{~s}$, rise time $\mathrm{tr}=0.4 \mathrm{~s}$ and the SSE is 0.3 . It is clear that the response recovers to its set point with lower steady state error and the $\mathrm{P}$ controller possess better dynamic response and both overshoots and steady state error are minimized.

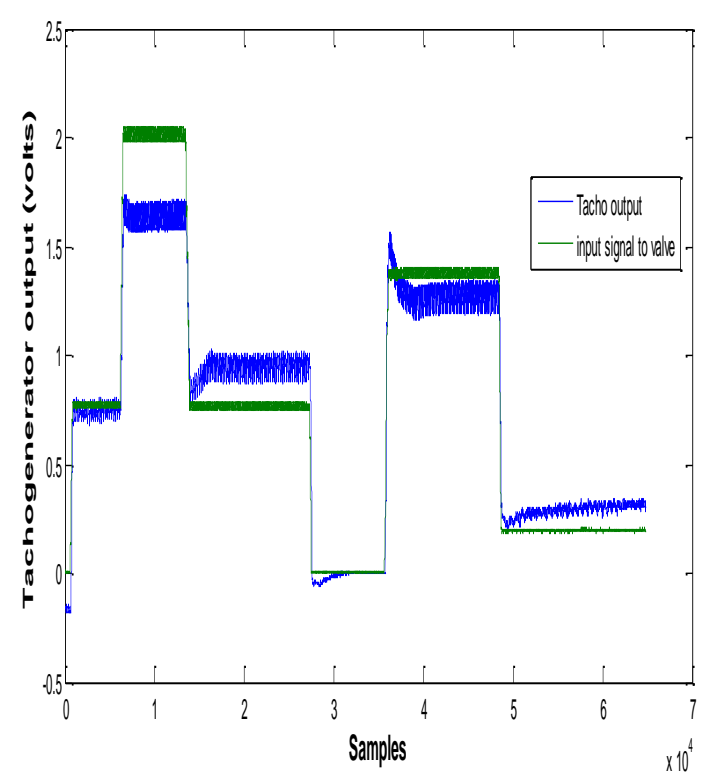

Fig(12) Transient response of EHSM with P- controller $\mathrm{Kb}=0.105$

\section{Conclusion}

This paper introduce a significant aspect of an integrated study of modeling, analysis and simulation of the dynamic response of electro hydraulic servo motor in order to spot more light on the complicated role played by the motor nonlinearities. The results submitted here are based on physical parameters of studied system, which significantly influence the response of the motor and the behavior of the plant with respect to various types of load input.

The good agreement between the experimental and the simulation results validates the proposed model and expressed the precision of the mathematical model. Therefore, the proposed model can be used to predict the performance of electro hydraulic servo motors systems and to provide the criteria for improving the design of the system. The model still contains several critical parameters those substantially influence the dynamic response performance of the system within the range of operation considered.

Better tracking for the system desired output is obtained by introducing a P- controller with velocity feedback loop.

Introducing different intelligent controllers under different inputs and feedback loops will give more satisfied and better dynamic performance.

Due to the old age of the test servo mechanism EHS 160, the experimental results are obtained within a limited range and some fluctuation. However, it is obtained that the model developed will be useful for wider range of parameter variation. 


\section{References.}

[1]Z. Situm, Z. Cikovic,Optimization of control parametersfor servo hydraulic systems using genetic algorithms, HIDRAVLIKA - REGULACIJA,2014

[2] S. Wang, M. Tomovic, and H. Liu, Commercial Aircraft Hydraulic Systems: Shanghai Jiao Tong University Press Aerospace Series. Academic Press, 2015.

[3] J. Erjavec and R. Thompson, Automotive technology: a systems approach. Cengage learning, 2014.

[4] K.abowda, D.Dyke and S. Noroozi, Dynamic performance analysis of PID and Fuzzy logic controllers applicable in electro hydraulic servo actuators: 13th APCA International Conference on Automatic Control and Soft Computing (CONTROLO), 2018.

[5]https://www.hydraulicspneumatics.com/technologies/h ydraulic-valves/article/21882788/whats-thedifference-between-a-servovalve-and-aproportional-valve.

[6] K. Redberg, Hydraulic Servo Systems dynamic Properties and Control,Linköping University, 2014.

[7] T. Samakwong, W. Assawinchaichoteb, PID Controller Design for Electro-hydraulic Servo Valve System with Genetic Algorithm, International Electrical Engineering Congress, iEECON, 2016.

[8] M. Zaki, M.Rabie,A.Youssef, Optimization of Control Parameters Based on Genetic Algorithm Technique for Integrated Electrohydraulic Servo Actuator System. International Journal of Mechatronics and Automation. 2020, PP 24-37.

[9] Meng Tang, ShiDe Xiao, The Performance improvement in Electro-Hydraulic Servo System with PDF control, The 2nd International Conference on Computer and Automation Engineering (ICCAE), Singapore, 2010, pp. 871-875.

[10] FEEDBACK INSTRUMENTS LIMITED, Electrohydraulic servomechanism type EHS 160

\section{Nomenclature}

B Viscous damping coefficient of the load, Nms/rad

$\mathbf{C}_{\mathbf{d}}$ Discharge coefficient

$\mathbf{V}_{\mathbf{m}} \quad$ Volumetric displacement, $\mathrm{m}^{3} / \mathrm{rad}$

$\mathbf{K}_{\mathbf{a}}$ Amplifier gain

$\mathbf{K}_{\mathbf{c}} \quad$ Flow-pressure coefficient, $\mathrm{m}^{5} / \mathrm{N}$.s

$\mathbf{K}_{\mathbf{h}}$ Effective bulk modulus of the system.

K1 Total leakage coefficient of the motor, $\mathrm{m}^{5} / \mathrm{N}$.s

$\mathbf{K}_{\mathbf{p}}$ Proportional controller gain

$\mathbf{K}_{\mathbf{S}} \quad$ Position transducer constant, $\mathrm{V} / \mathrm{rad} / \mathrm{s}$

Kt Tachogenerator constant, V/rad/s

J Total inertial of motor and load, $\mathrm{Nms}^{2} / \mathrm{rad}$

QL Load flow, $\mathrm{m}^{3} / \mathrm{s}$

PL Load pressure, bar

$\mathbf{P}_{\mathbf{S}} \quad$ Supply pressure, bar

S Laplace operator

t Time, s

$\mathbf{V}_{\mathbf{t}}, \quad$ Total compressed volume, $\mathrm{m}^{3}$

$\mathbf{X}_{\mathbf{V}}$ Displacement of the spool in the servo valve, $\mathrm{m}$

\section{Greek Symbols}

$\theta \quad$ Shaft position, rad

$\dot{\theta}$ Angular velocity of the motor shaft, $\mathrm{rad} / \mathrm{s}$

o Fluid mass density, $\mathrm{kg} / \mathrm{m}^{3}$

$\tau_{x} \quad$ Valve time constant, $\mathrm{s}$ 